GRASAS Y ACEITES 67 (2)

April-June 2016, e127

ISSN-L: 0017-3495

doi: http://dx.doi.org/10.3989/gya.0627152

\title{
Determination of saturated aliphatic hydrocarbons in vegetable oils
}

\author{
R.B. Gómez-Coca ${ }^{\bowtie}$, R. Cert, M.C. Pérez-Camino and W. Moreda \\ Department of Characterization and Quality of Lipids, Instituto de la Grasa - CSIC-Campus \\ of Universidad Pablo de Olavide, Building 46, Ctra. Utrera km 1, 41013 Seville, Spain \\ ${ }^{\square}$ Corresponding author: raquel.coca@ig.csic.es
}

Submitted: 10 June 2015; Accepted: 13 October 2015

SUMMARY: The aim of this work is to inform about the development of a simple and reliable off-line method for the determination of saturated hydrocarbons $(\mathrm{SH})$ in vegetable oils. $\mathrm{SH}$ can be used as markers for fuel or for mineral oil contamination in edible oils and fats. The method consists of the isolation of the fraction by LC on deactivated silver-silica gel and subsequent on-column GC-FID analysis. This stationary phase was prepared avoiding any kind of activation. The method was developed and validated through the participation in both a proficiency test organized by the Joint Research Centre of the European Commission, and a collaborative trial carried out with trained Spanish laboratories according to the standard ISO 5725. Results showed acceptable repeatability and reproducibility values, and Horrat index, being this protocol in use with satisfactory results ever since. The method's LOQ is $15 \mathrm{mg} \cdot \mathrm{kg}^{-1}$ and its LOD $5 \mathrm{mg} \cdot \mathrm{kg}^{-1}$, which make it suitable to quantify the $50 \mathrm{mg} \cdot \mathrm{kg}^{-1} \mathrm{limit}$ established by the EU, and to detect mineral oil content within the $10-500 \mathrm{mg} \cdot \mathrm{kg}^{-1}$ range. Although other procedures with lower LOD have been developed throughout the years, the use of just regular laboratory equipment such as GC-FID makes the proposed method appropriate for application on a routine basis.

KEYWORDS: Fuel-oil; Mineral oil; Saturated hydrocarbons; Silver-silica gel fractionation; Unresolved Complex Mixture (UCM)

RESUMEN: Determinación de hidrocarburos alifáticos saturados en aceites vegetales. El objetivo de este trabajo es el de dar cuenta del desarrollo de un método sencillo y fiable para la determinación de hidrocarburos saturados (HS) en aceites vegetales. Los HS pueden utilizarse como marcadores de contaminación de aceites y grasas comestibles con fuel-oil y aceites minerales El procedimiento consiste en el aislamiento de la fracción correspondiente por cromatografía en columna de gel de sílice argentada sin activar y posterior análisis mediante GC (on-column)-FID. El método se desarrolló y validó mediante la participación en una prueba de competencia organizada por el Joint Research Centre de la Comisión Europea, además de con un ensayo colaborativo llevado a cabo por laboratorios españoles de acuerdo con la norma ISO 5725. Los resultados mostraron valores de repetibilidad y de reproducibilidad aceptables, así como del índice de Horrat, por lo que dicho protocolo se está utilizado con resultados muy satisfactorios. El límite de detección (LDD) es de $5 \mathrm{mg} \cdot \mathrm{kg}^{-1}$, y su límite de cuantificación (LDQ) de $15 \mathrm{mg} \cdot \mathrm{kg}^{-1}$, lo que lo hacen muy adecuado para evaluaciones alrededor del límite de $50 \mathrm{mg} \cdot \mathrm{kg}^{-1}$ establecido por la Unión Europea (UE). Asimismo es fiable para determinar el contenido de aceite mineral en el intervalo entre 10 y $500 \mathrm{mg} \cdot \mathrm{kg}^{-1}$. Si bien se han desarrollado otros procedimientos con menor LDD a lo largo de los años, el uso de equipos habituales de laboratorio tales como GC-FID ha hecho que el método propuesto sea el de elección para su aplicación en cualquier laboratorio de forma rutinaria.

PALABRAS CLAVE: Aceite mineral; Fraccionamiento mediante sílica argentada; Fuel-oil; Hidrocarburos saturados; Mezcla compleja sin resolver (UCM)

Citation/Cómo citar este artículo: Gómez-Coca RB, Cert R, Pérez-Camino MC, Moreda W. 2016. Determination of saturated aliphatic hydrocarbons in vegetable oils. Grasas Aceites 67 (2): e127. doi: http://dx.doi.org/10.3989/gya.0627152.

Copyright: (C) 2016 CSIC. This is an open-access article distributed under the terms of the Creative Commons Attribution-Non Commercial (by-nc) Spain 3.0 Licence. 


\section{INTRODUCTION}

Crude edible vegetable oils contain various classes of natural hydrocarbons: $50-350 \mathrm{mg} \cdot \mathrm{kg}^{-1}$ of the n-alkane series from $\mathrm{C} 10$ to $\mathrm{C} 35$, centred at $\mathrm{C} 25-\mathrm{C} 29$, the odd numbered elements being the most abundant; squalene that is the major hydrocarbon in olive and pumpkin oils $\left(500-12000 \mathrm{mg} \cdot \mathrm{kg}^{-1}\right)$; and low amounts of the $\mathrm{n}$-alkene series and terpenic hydrocarbons (sesquiterpenes in olive oil, kaurene in sunflower oil). These compounds, when analysed by high-resolution gas chromatography-flame ionization detector (GC-FID), yield a GC profile constituted by numerous sharp peaks that can be easily quantified (Lanzón et al., 1994).

On the other hand, base oil for manufacturing the lubricating or hydraulic oils used in the food industry, named "white mineral oil", is constituted by a complex mixture of branched saturated aliphatic hydrocarbons (mainly iso-isomers) that yield a GC-FID hump between $\mathrm{C} 20$ and C54, known as unresolved complex mixture (UCM). In GC-FID chromatograms obtained from the hydrocarbon fraction of vegetable oils, mineral oil contamination can be evidenced by the presence of a hump of branched saturated hydrocarbons $(\mathrm{SH})$ with a series of sharp peaks on the top corresponding to the $n$-alkanes.

Nevertheless in refined vegetable oils, significant amounts of unsaturated steroidal hydrocarbons coming from dehydration of sterols are found, and in refined olive oils, isoprenoid alkenes from isomerization and cyclization of squalene and from dehydration and cyclization of oxidized squalene are found too (Lanzón et al., 1994; Bastic et al., 1978). All these compounds yield a very complex GC-FID profile between C20 and C35 overlapping with the hump due to mineral oil. Therefore, the determination of mineral oil in vegetable oils requires the isolation of a $\mathrm{SH}$-fraction from the unsaturated ones.

GC-FID is the technique of choice for the analysis of the SH fraction because it enables the determination of SH naturally present in fats and oils, and the hump of branched paraffins from mineral oils. The use of silica gel high performance liquid chromatography (HPLC) as a first step to separate the paraffins from the rest of the oil has also been described (Fiselier et al., 2009a). Mineral paraffins are determined by the area of the hump, confined by the baseline and an upper contour line defined by the base line of the sharp (natural) peaks standing on the hump.

Some years ago about $1000 \mathrm{mg} \cdot \mathrm{kg}^{-1}$ of a mixture mainly constituted of saturated aliphatic hydrocarbons ranged from $\mathrm{C} 18$ to $\mathrm{C} 40$ (centred at $\mathrm{C} 28$ ) was found in crude sunflower oil coming from Ukraine, and attributed to contamination with mineral oil (Biedermann et al., 2009). To protect consumers the European Commission decided to consider the UCM of $\mathrm{SH}$ as marker of mineral oil and established a legal limit of $50 \mathrm{mg} \cdot \mathrm{kg}^{-1}$ from $\mathrm{C} 10$ to C56 (except n-C27, n-C29, and n-C31) in sunflower oils (EC, 2009). At that moment, IUPAC, 1987 and AOCS, 1997 methods were standardized for the control of this contaminant in oils and fats; in the former, the oil is fractioned by thin layer chromatography (TLC) on silica gel plates and determined by the densitometry of the spot; the latter lies in the weight of the SH-fraction isolated by column chromatography (CC) on alumina. Both methods suffered from a high detection limit (500-1000 $\mathrm{mg} \cdot \mathrm{kg}^{-1}$ ) and consequently, new methods based on the chromatographic isolation of SH-fraction and posterior analysis by GC-FID were developed to detect lower amounts of mineral oil.

For the isolation of SH-fraction from the oil $\mathrm{CC}$ on alumina, silica gel, and their combinations have been proposed. Studies on the behaviour of different classes of paraffins (n-, iso-, large carbonatom number) on alumina showed that the retention depends on the aluminium oxide activation temperature, mobile phase, column temperature, sensitivity to polar components and capacity (Fiselier et al., 2009a; Fiselier et al., 2009b; Wagner et al., 2001), and that a partial loss of iso-paraffins may occur (Moret et al., 2011). These results indicate that alumina is not advisable for the quantitative determination of mineral oil.

Silica gel has been usually applied for the isolation of the SH-fraction from the oil, using solid phase extraction (SPE) (Fiorini et al., 2010), liquid chromatography (LC) (Tan and Kuntom, 1993) and especially on-line HPLC-GC (Tranchida et al., 2011; Biedermann and Grob, 2012). A separation by SPE packed with alumina and silica gel on top, followed by GC-FID analysis with large volume on-column injection has been described (Fiselier and Grob, 2009). These methods reach sufficient sensitivity but the separation from the unsaturated hydrocarbons is not complete in refined oils containing significant amounts of sterenes or squalene. To improve resolution and sensitivity, on-line HPLC-HPLC-GC-FID systems have been proposed where the first column isolates the hydrocarbons from the bulk of the oil and the second one separates the paraffins (Fiorini et al., 2008; Populin et al., 2004; Neukom et al., 2002). These methods require somehow more sophisticated apparatus that may not be available in many laboratories.

Other approaches to improve the isolation of the $\mathrm{SH}$-fraction from the oil consist of the fractioning of the unsaponifiable matter on silica gel column, rendering better sensitivity and separation (Lanzón et al., 1994), and the bromination (Wagner et al., 2001; Moret et al., 2003) or epoxidation (Biedermann and Grob, 2012; Biedermann et al., 2009) of the oil to obtain more polar derivatives of the unsaturated compounds that are more strongly retained during LC. These procedures are solvent- and time consuming, tedious, and prone to contamination. 
The use of silver-silica enhances the separation between the $\mathrm{SH}$-fraction and the olefins due to the affinity of the $\mathrm{Ag}^{+}$ion to double bonds (olefinic and aromatic hydrocarbons) allowing a more reliable fractioning. An off-line method based on SPE on activated silver-silica gel mixture $(1 \mathrm{~g})$ followed by GC-FID has been reported (Moret et al., 2011) for the determination of mineral oil in vegetable oils.

The aim of this work was to inform about the development of a simple and reliable off-line method for the determination of $\mathrm{SH}$ as markers of fuel or mineral oil contamination in edible oils and fats. The criteria were (i) availability of samples containing large amounts of interfering olefins and (ii) wide concentration range including the legal limit of $50 \mathrm{mg} \cdot \mathrm{kg}^{-1}$ established by the European Commission for Ukrainian sunflower oil (EC, 2009). The method consists of the isolation of the fraction by LC on deactivated silver-silica gel and subsequent on-column GC-FID analysis. This stationary phase was prepared by a new procedure avoiding the activation used for the isolation of steroidal hydrocarbons in vegetable oils (Cert and Moreda, 1998).

\section{MATERIALS AND METHODS}

\subsection{Samples}

Samples of sunflower oil coming from Ukraine were obtained from the Spanish Food Safety Agency. Samples of crude and refined sunflower oils were purchased in the local markets. Refined pomace oil was obtained directly from the producers.

\subsection{Material and reagents}

All the reagents were of analytical grade unless otherwise specified. Distilled water, sea sand, and silver nitrate were purchased from Panreac (Montcada I Reixac, Barcelona, Spain). 3,5-Cholestadiene and the internal standard (IS) n-eicosane (C20) were from Sigma-Aldrich Co. LLC (St. Louis, Missouri, USA). Diethyl ether, n-heptane, and n-hexane 95\% were supplied by Romil Ltd. (Waterbach, Cambridge, GB). We checked the n-hexane purity by concentrating a mixture of $200 \mathrm{~mL}$ of the solvent with $2 \mathrm{~mL}$ of the IS (C20) in a rotary evaporator down to $0.5 \mathrm{~mL}$, and analysing the concentrate by GC with cool on-column injection. Silica gel 60 for column chromatography, 70-230 mesh, (Merck KGaA, Darmstadt, Germany) was used directly from the container. A silver nitrate solution $(75 \% \mathrm{w} / \mathrm{v})$ was prepared by dissolving $4.5 \mathrm{~g}$ of silver nitrate in $6 \mathrm{~mL}$ distilled water. Chromatography columns $(50 \mathrm{~cm}$ long $\times 1.5 \mathrm{~cm}$ id) were provided with Teflon stopcocks and were washed with n-hexane before use.

\subsection{Method development}

\subsubsection{Separation of the hydrocarbon fractions}

Deactivated $10 \%$ silver-silica gel was prepared following the procedure indicated for the separation of steroidal hydrocarbons (Cert and Moreda, 1998) but decreasing the water proportion down to $13.3 \% \mathrm{w} / \mathrm{v}$

For the preparation of 3 chromatography columns, $45 \mathrm{~g}$ silica gel were weighted in a $500-\mathrm{mL}$ round-bottomed flask; thereafter $6 \mathrm{~mL}$ silver nitrate solution were added drop wise with a Pasteur pipette, shaking then vigorously. The flask was covered with aluminium foil and put in a rotary evaporator during $30 \mathrm{~min}$ at room temperature and atmospheric pressure. To avoid uneven distribution of the silver nitrate in the silica gel both the condenser and the evaporation flask were set horizontally. Finally it was let to stand during $12 \mathrm{~h}$ before use.

For each column arrangement, $15 \mathrm{~g}$ of silversilica gel were suspended in a beaker in n-hexane, and the slurry was introduced onto the chromatographic column already containing $40 \mathrm{~mL}$-hexane. Once the packing settled, a small amount of sea sand (previously washed with n-hexane) was added $(1 \mathrm{~cm}$ of column height), and the remaining solvent eluted. In order to avoid bubble formation, we tapped the column gently with a rubber rod. The column was eluted with $60 \mathrm{~mL}$-hexane to eliminate impurities of the packing material, and wrapped in black paper to protect it from the light.

To investigate the behaviour of the different types of hydrocarbons during the chromatographic separation on silver-silica gel column, refined olive pomace oil spiked with 3,5-cholestadiene was chosen. In a small beaker, $1 \mathrm{~g}$ oil was weighed to the nearest $1 \mathrm{mg}$, and $1 \mathrm{~mL} \mathrm{3,5-cholestadiene} \mathrm{standard} \mathrm{solution} \mathrm{was}$ added. The mixture was transferred to the column with the aid of a Pasteur pipette and let get in the stationary phase. The beaker was washed with two portions of $1 \mathrm{~mL}$-hexane that were also added to the column packing. The column was then eluted with $100 \mathrm{~mL}$ n-hexane with a cadence of 15 drops every $10 \mathrm{~s}$ approximately, collecting three separated fractions of 40,40 , and $20 \mathrm{~mL}$, respectively. Subsequently, $120 \mathrm{~mL}$ of the n-hexane:diethyl ether $(98: 2, \mathrm{v} / \mathrm{v}) \mathrm{mix}-$ ture were added, collecting three independent $40 \mathrm{~mL}$ fractions. Most of the solvent of each fraction was evaporated in a rotary evaporator at room temperature under vacuum and until dryness with a nitrogen stream. Each residue was re-dissolved in $0.5 \mathrm{~mL}$ n-heptane and analysed by GC.

\subsubsection{Gas chromatography analysis and quantitation}

GC analysis of the hydrocarbons was performed using an Agilent $6890 \mathrm{~N}$ gas chromatograph (Agilent Technologies, Santa Clara, California) equipped 
with an Agilent 7683B Automatic Liquid Sampler and FID. Data was acquired with the Agilent ChemStation for GC system program. Separations were carried out on a high-temperature fused-silica capillary column (5\% diphenyl-95\% dimethylpolysiloxane: $10 \mathrm{~m} \times 0.32 \mathrm{~mm}$ id, $0.10 \mu \mathrm{m}$ film; Sugelabor, Madrid, Spain), $2 \mu \mathrm{L}$ injection volume, hydrogen carrier gas at $105 \mathrm{kPa}$ and EPC cool on-column injection. The operating conditions were as follow: injector temperature, $60{ }^{\circ} \mathrm{C}$; detector temperature,
$350{ }^{\circ} \mathrm{C}$; oven programming temperatures, initial $60{ }^{\circ} \mathrm{C}$ for $1 \mathrm{~min}$ and then rising at $12{ }^{\circ} \mathrm{C} \cdot \mathrm{min}^{-1}$ to $350{ }^{\circ} \mathrm{C}$, hold for $4 \mathrm{~min}$. Under these conditions the IS (C20) appeared at a retention time of about 8.5 min (Figure 1).

For the quantitative determination of both natural $n$-alkanes and UCM, the sum of the respective areas, except that of the IS, was considered. On each case those areas were compared with the area of the IS.

(A)

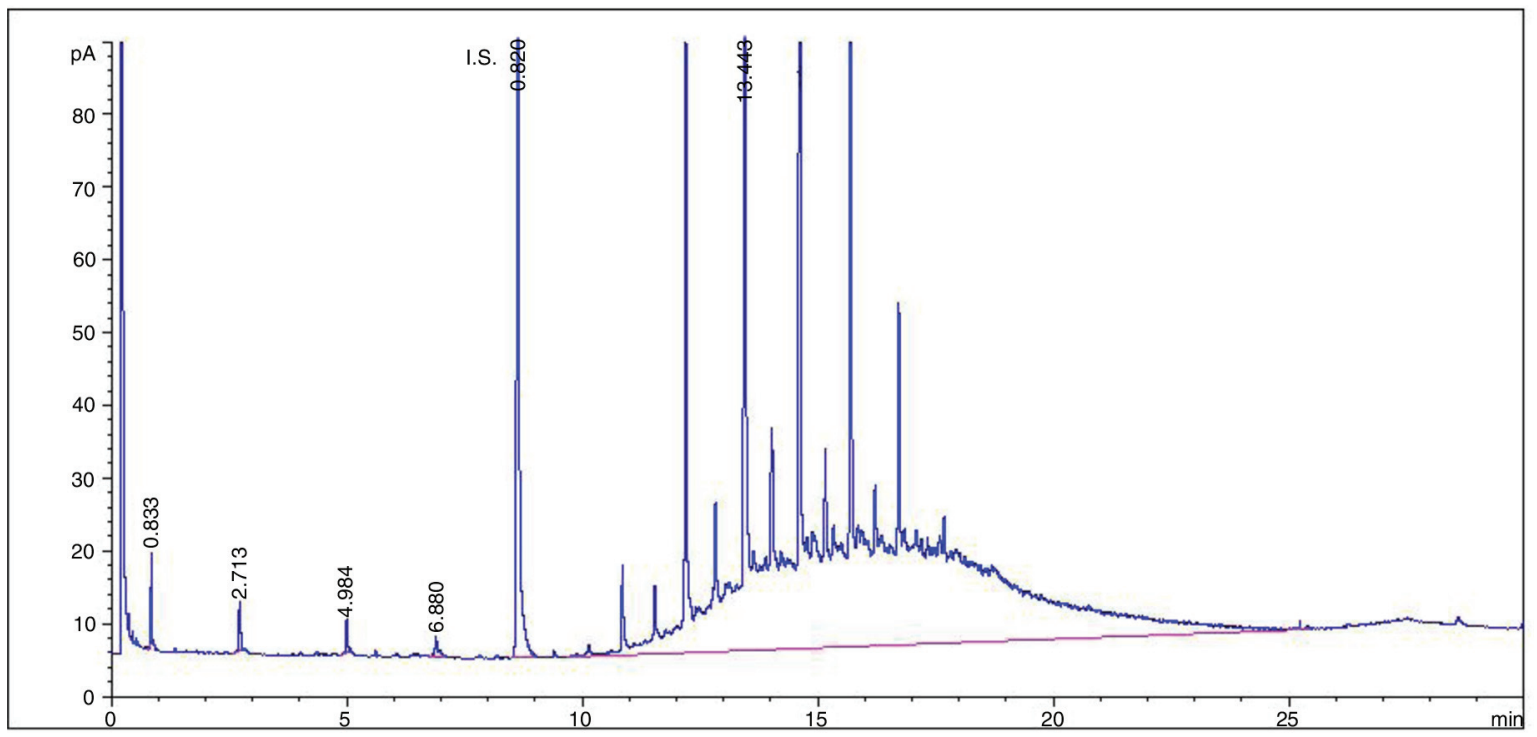

(B)

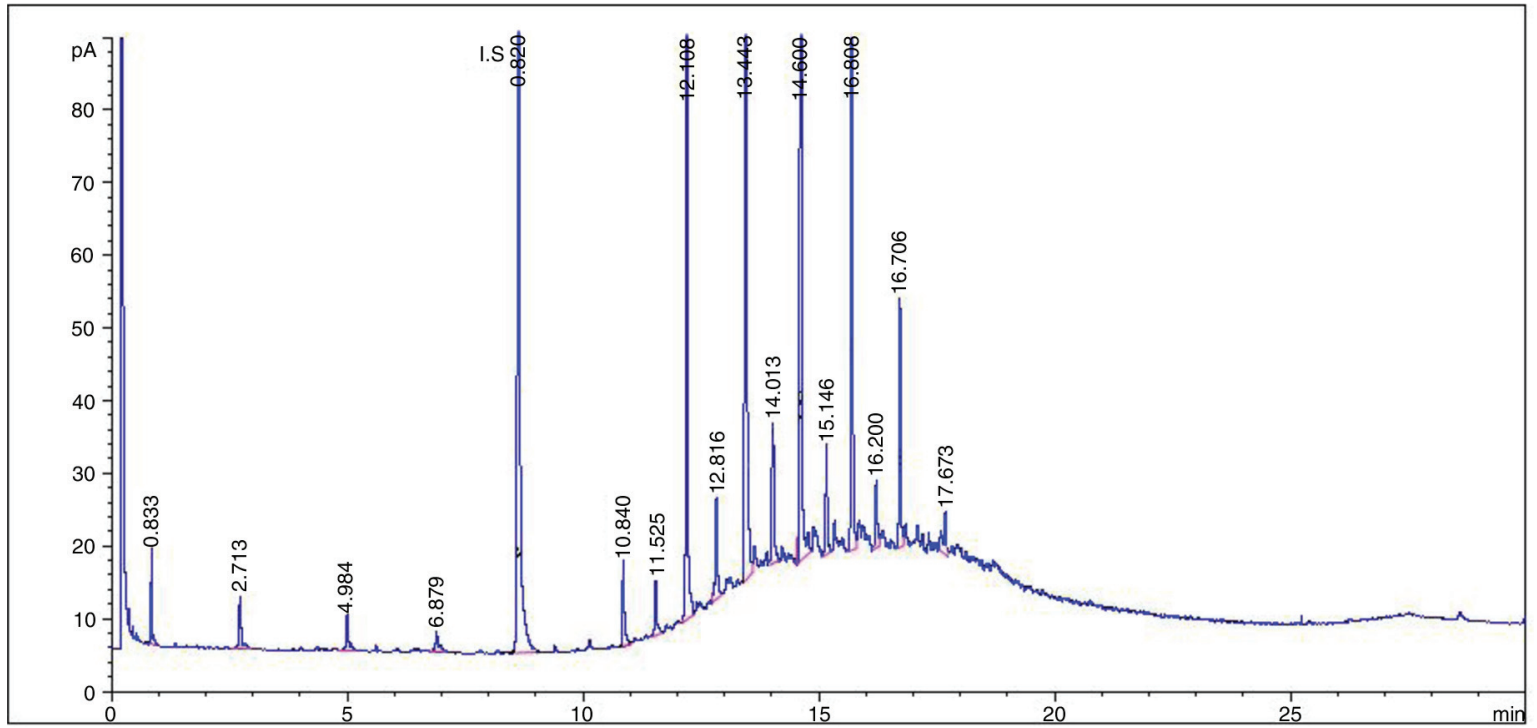

Figure 1. GC profile of the first $40 \mathrm{~mL}$-n-hexane fraction containing $\mathrm{SH}$ from refined olive-pomace oil. IS $=\mathrm{C} 20$. Oven temperature ramp: $12^{\circ} \mathrm{C} \cdot \mathrm{min}^{-1}$. A) Manual baseline traced under hump. B) Baseline traced valley-valley under the natural $n$-alkane peaks. The main peaks at retention time from 12.1 to 16.7 minutes correspond to the odd series from C23 to C29. 


\subsection{Method validation}

Mineral oil type B (ref. 78473, Fluka, Buchs, Switzerland) was constituted by paraffins from $\mathrm{C} 19$ to $\mathrm{C} 41$ with maximum at $\mathrm{C} 27$. For de calculation of the response factor, $1 \mathrm{~mL}$ portions of this mineral oil in n-hexane were prepared at concentrations of $20,51,101$, and $507 \mathrm{mg} \cdot \mathrm{L}^{-1}$, by dilution of a $1014 \mathrm{mg} \cdot \mathrm{L}^{-1}$ solution. Refined sunflower oil samples containing $491,105,51,19$, and $11 \mathrm{mg} \cdot \mathrm{kg}^{-1}$ mineral oil were prepared by mixing mineral oil type B and a "blank" refined sunflower oil containing less than $5 \mathrm{mg} \cdot \mathrm{kg}^{-1}$ hydrocarbons (method's LOD).

The IS usually applied for the quantification of the $\mathrm{SH}$ was a solution of n-eicosane (C20) in n-hexane at concentration of $0.05 \mathrm{mg} \cdot \mathrm{mL}^{-1}$. This is the smallest natural $n$-alkane in the majority of vegetable oils. However, in the case of vegetable oils containing significant amounts of natural n-eicosane other $n$-alkane must be chosen; that is the case of corn oil, where the use of n-nonadecane (C19) is recommended.

The spiked mineral oil solutions were evaporated in a rotary evaporator at room temperature under negative pressure. The residues were re-dissolved in n-heptane and analysed by GC. Other spiked portions $(1 \mathrm{~mL})$ were fractioned through silver-silica gel column and each time the first $60-\mathrm{mL}$ fraction were analysed by GC.

To evaluate the effect of oil matrix, refined sunflower oil samples containing 491, 105, 51 and $19 \mathrm{mg} \cdot \mathrm{kg}^{-1}$ mineral oil were prepared by blending mineral oil type B and a "blank" refined sunflower oil that yielded an analytical result below the method's LOD.

Repeatability at $50 \mathrm{mg} \cdot \mathrm{kg}^{-1}$ level was calculated analysing the oil sample containing $51 \mathrm{mg} \cdot \mathrm{kg}^{-1}$ six times consecutively.

The LOD was determined using the "blank" refined sunflower oil fortified with $10 \mathrm{mg} \cdot \mathrm{kg}^{-1}$ mineral oil.

\section{RESULTS AND DISCUSSION}

\subsection{Method development}

\subsubsection{Separation of the hydrocarbon fractions}

As pointed out before, to study the behaviour of the different types of hydrocarbons during the separation on silver-silica gel column, refined olive pomace oil spiked with 3,5-cholestadiene was chosen since it contains significant amounts of squalene and its derivatives, and steroidal hydrocarbons. The oil $(1 \mathrm{~g})$ was fractioned in the silver-silica gel column collecting three separated fractions of 40,40 , and $20 \mathrm{~mL}$ n-hexane, respectively. Subsequently, $120 \mathrm{~mL}$ of the n-hexane:diethyl ether (98:2) mixture were added, collecting three independent $40 \mathrm{~mL}$ fractions. Each fraction was analysed by GC. The first $40-\mathrm{mL}$ fraction contained natural SH and UCM (Figure 1). Negligible amounts of compounds were found in the second $40-\mathrm{mL}$ fraction, whereas a small peak of stigmastadiene appears in the third $20-\mathrm{mL}$ fraction. The subsequent elution with $40 \mathrm{~mL}$-hexane:diethyl ether (98:2) extracted cholestadiene and stigmastadiene and with an additional $40 \mathrm{~mL}$-portion of the same solvent, a complex mixture of hydrocarbons and (aliphatic and terpenic) waxes was obtained. Finally, the GC chromatogram of a new $40-\mathrm{mL}$ fraction showed alkyl esters of fatty acids and waxes together with some other humps. Squalene remained in the column. These facts indicate that a very good separation between SH and other compounds is achieved using silver-silica gel. Elution with $60 \mathrm{~mL} \mathrm{n}$-hexane (first fraction) is more than enough to assure a complete isolation of this fraction without interferences of other compounds, and there is no need to collect further eluates.

\subsubsection{Gas chromatography analysis and quantitation}

The analysis of the SH fraction coming from a contaminated vegetable oil yields a gas chromatogram showing a broad chromatographic hump of about 15 min width due to an UCM of branched hydrocarbons typical of mineral oils. On this hump, a series of sharp peaks corresponding to $n$-alkanes naturally present in vegetable oils appears. For the quantitative determination of the UCM, a straight baseline was traced using "manual integration", from the beginning of the hump (just after the C20 IS has eluted) until the point where the trace returns to the baseline, resulting in the area of the hump and all the peaks on it (Figure 1A). Next, new valley-valley integrations were performed under each sharp peak appearing on the hump; the areas of all peaks corresponding to the $n$-alkane series were added (Figure 1B). The difference between the former and the latter integration results was the area of the UCM. For the determination of the natural $n$-alkanes, the sum of the areas of corresponding sharp peaks, except that of the IS, was considered. For quantification, the areas of the UCM and those of the natural $n$-alkanes were compared with the area of the IS.

\subsection{Method validation}

One $\mathrm{mL}$ Portions of spiked mineral oil type B solutions were analysed by GC. Other spiked portions $(1 \mathrm{~mL})$ were fractioned thorough silver-silica gel column and analysed also by GC. For concentrations lower than $500 \mathrm{mg} \cdot \mathrm{kg}^{-1}$ response factors with respect to the C20 IS were about 1.02, and recoveries vs. direct analysis, and vs. standard solutions were higher than 95 and $93 \%$, respectively (Table 1), indicating minimum losses.

To evaluate the effect of oil matrix, "blank" refined sunflower oil samples were mixed at certain 
TABLE 1. Responses of direct analysis and recoveries of analysis through silver-silica gel column of mineral oil type B standard solutions in n-hexane

\begin{tabular}{lccccc}
\hline $\begin{array}{l}\text { Standard solution of } \\
\text { mineral oil }\left(\mathbf{m g} \cdot \mathbf{L}^{-1}\right)\end{array}$ & $\begin{array}{c}\text { Direct analysis by } \\
\mathbf{G C}\left(\mathbf{m g} \cdot \mathbf{L}^{-1}\right)\end{array}$ & $\begin{array}{c}\text { GC analysis after } \\
\text { passing through } \\
\text { column }\left(\mathbf{m g} \cdot \mathbf{L}^{-1}\right)\end{array}$ & $\begin{array}{c}\text { Recovery vs. direct } \\
\text { analysis }(\%)\end{array}$ & $\begin{array}{c}\text { Recovery vs. standard } \\
\text { solution }(\%)\end{array}$ \\
\hline 1014 & 983 & 96.9 & 909 & 92.5 & 89.6 \\
507 & 493 & 97.2 & 472 & 95.7 & 93.1 \\
101 & 98 & 97.0 & 95 & 96.9 & 94.1 \\
51 & 50 & 98.0 & 49 & 98.0 & 96.1 \\
20 & 21 & 105.0 & 20 & 95.2 & 100.0 \\
\hline
\end{tabular}

concentrations with mineral oil type $\mathrm{B}$. The analysis of these oils using the proposed method produced recoveries of $93.3,96.2,102.1$, and $110.5 \%$ with respect to the added mineral oil, and 92.7, 93.5, 96.0, and $95.5 \%$ taking into account the content of the "blank oil" (below $5 \mathrm{mg} \cdot \mathrm{kg}^{-1}$ ). These results indicate that the calibration curve obtained from n-hexane solutions can be used for quantification purposes.

Repeatability at $50 \mathrm{mg} \cdot \mathrm{kg}^{-1}$ level was calculated analysing the oil sample containing $51 \mathrm{mg} \cdot \mathrm{kg}^{-1}$. The standard deviation (SD) was $\pm 1.9 \mathrm{mg} \cdot \mathrm{kg}^{-1}$ and the variation coefficient $4.0 \%$.

A LOD of $5 \mathrm{mg} \cdot \mathrm{kg}^{-1}$ was estimated using the "blank" refined sunflower oil fortified with $10 \mathrm{mg} \cdot \mathrm{kg}^{-1}$ mineral oil. The LOQ was approximately $15 \mathrm{mg} \cdot \mathrm{kg}^{-1}$, three times the LOD, although it depends on the width of hump. This LOQ is sufficient to quantify around the $50 \mathrm{mg} \cdot \mathrm{kg}^{-1}$ limit established by the EU.

The aim of the present work was to develop a reliable and robust analytical method for the detection of mineral and fuel oil in edible fats and oils, which let compare results to those obtained by other methods. At this point, we participated in the proficiency test organized by The JRC of the European Commission on the determination of mineral oil in sunflower oils (Joint Research Centre, 2009) where each of the 55 laboratories used its own method. The results obtained using the method proposed in this paper are shown in Table 2. It can be seen that they are comparable with those obtained by other procedures.

\subsection{Collaborative trial}

A collaborative trial was carried out with trained Spanish laboratories according to the standard ISO 5725. Samples of "blank" refined sunflower oil, "blank" samples spiked with $51 \mathrm{mg} \cdot \mathrm{kg}^{-1}$ mineral oil type $\mathrm{B}$, and highly contaminated crude sunflower oil samples were run by nine laboratories following the method described under Section 2.5, emphasizing the integration requirements. The results are shown in Table 3.

A lower precision for determinations of total and UCM hydrocarbons in samples containing
TABLE 2. Comparison of results of mineral oil determination obtained in the proficiency test organized by the Joint Research Centre of the EU

\begin{tabular}{lccc}
\hline & $\begin{array}{c}\text { Results using } \\
\text { the proposed } \\
\text { method } \\
\left(\mathbf{m g} \cdot \mathbf{k g}^{-1}\right)\end{array}$ & $\begin{array}{c}\text { Mean value } \\
\text { after removal } \\
\text { of outliers } \\
\left(\mathbf{m g} \cdot \mathbf{k g}^{-1}\right)\end{array}$ & $\begin{array}{c}\text { Gravimetrically } \\
\text { established } \\
\text { value } \\
\left(\mathbf{m g} \cdot \mathbf{k g}^{-\mathbf{1}}\right)\end{array}$ \\
\hline $\begin{array}{l}\text { Crude } \\
\text { sunflower oil }\end{array}$ & 381 & 358 & - \\
$\begin{array}{l}\text { Refined } \\
\text { sunflower oil }\end{array}$ & 123 & 113 & - \\
$\begin{array}{l}\text { Refined } \\
\text { sunflower oil } \\
\text { spiked with } \\
\text { mineral oil }\end{array}$ & 103 & 120 & 114 \\
\hline
\end{tabular}

a hump of compounds can be observed, which suggests that the layout of the base line between the beginning and the end of the hump is the main source of error. This trouble is common to all methods for determining mineral oil using $\mathrm{GC}$ analysis.

\subsection{Final remarks: GC temperature programme}

In order to improve the precision of the method an increase in the ramp rate of the GC oven temperature was proposed (Moret et al., 2011) since the width of the hydrocarbon hump was reduced; however, special care must be taken to avoid overlapping of this hump with the possible change of the baseline when the final temperature is reached. The baseline change with $20{ }^{\circ} \mathrm{C} \cdot \mathrm{min}^{-1}$ ramp occurs at shorter retention time than with $12{ }^{\circ} \mathrm{C} \cdot \mathrm{min}^{-1}$ (Figure 2) producing the alteration of the hump profile appearing in olive-pomace oil analysis (comparing Figures 1 and 3).

\section{CONCLUSIONS}

The method is reliable for mineral oil detection in the range $10-500 \mathrm{mg} \cdot \mathrm{kg}^{-1}$. At level of the limit established by the EU for mineral oil in sunflower oil $\left(50 \mathrm{mg} \cdot \mathrm{kg}^{-1}\right)$, the repeatability and reproducibility values, and the Horrat index were acceptable (Table 3), 
TABLE 3. Precision data for the determination of various types of saturated hydrocarbons $(\mathrm{SH})$ in refined, spiked and contaminated crude sunflower oils

\begin{tabular}{|c|c|c|c|c|c|c|c|c|c|}
\hline & \multicolumn{3}{|c|}{ "Blank" refined sunflower oil } & \multicolumn{3}{|c|}{$\begin{array}{l}\text { "Blank" refined sunflower oil spiked } \\
\text { with } 51 \mathrm{mg} \cdot \mathrm{kg}^{-1} \text { mineral oil type B }\end{array}$} & \multicolumn{3}{|c|}{$\begin{array}{l}\text { Contaminated crude } \\
\text { sunflower oil }\end{array}$} \\
\hline & Total SH & n-alkanes & $\mathbf{U C M}$ & Total SH & n-alkanes & $\mathbf{U C M}$ & Total SH & n-alkanes & UCM \\
\hline $\begin{array}{l}\text { Laboratories retained after } \\
\text { eliminating outliers }\end{array}$ & 8 & 8 & 8 & 9 & 9 & 9 & 9 & 9 & 9 \\
\hline $\begin{array}{l}\text { Number of test results on } \\
\text { sample }\end{array}$ & 16 & 16 & 16 & 18 & 18 & 18 & 18 & 18 & 18 \\
\hline Mean, $\mathrm{mg} \cdot \mathrm{kg}^{-1}$ & 159.6 & 157.9 & 1.6 & 214.2 & 160.3 & 53.9 & 508.1 & 126.1 & 382.0 \\
\hline $\begin{array}{l}\text { Repeatability standard } \\
\text { deviation }(\mathrm{Sr})\end{array}$ & 3.4 & 2.8 & 1.3 & 4.2 & 2.6 & 2.7 & 11.9 & 5.0 & 10.1 \\
\hline $\begin{array}{l}\text { Repeatability relative } \\
\text { standard deviation }(R S D r), \%\end{array}$ & 2.1 & 1.7 & 81.0 & 1.9 & 1.6 & 5.0 & 2.3 & 4.0 & 2.7 \\
\hline Repeatability limit $(r)$ & 9.5 & 7.7 & 3.7 & 11.7 & 7.4 & 7.5 & 33.3 & 14.0 & 28.4 \\
\hline $\begin{array}{l}\text { Reproducibility standard } \\
\text { deviation }\left(S_{R}\right)\end{array}$ & 7.3 & 6.6 & 2.0 & 14.3 & 8.2 & 8.1 & 30.6 & 6.4 & 30.7 \\
\hline $\begin{array}{l}\text { Reproducibility relative } \\
\text { standard deviation }\left(R S D_{R}\right), \%\end{array}$ & 4.6 & 4.2 & 122.3 & 6.7 & 5.1 & 14.9 & 6.0 & 5.0 & 8.1 \\
\hline Reproducibility limit $(R)$ & 20.3 & 18.5 & 5.6 & 39.9 & 22.8 & 22.5 & 85.6 & 17.8 & 86.1 \\
\hline Horrat Index $(H o R)$ & 0.22 & 0.20 & 2.91 & 0.33 & 0.24 & 0.60 & 0.34 & 0.23 & 0.44 \\
\hline
\end{tabular}

(A)

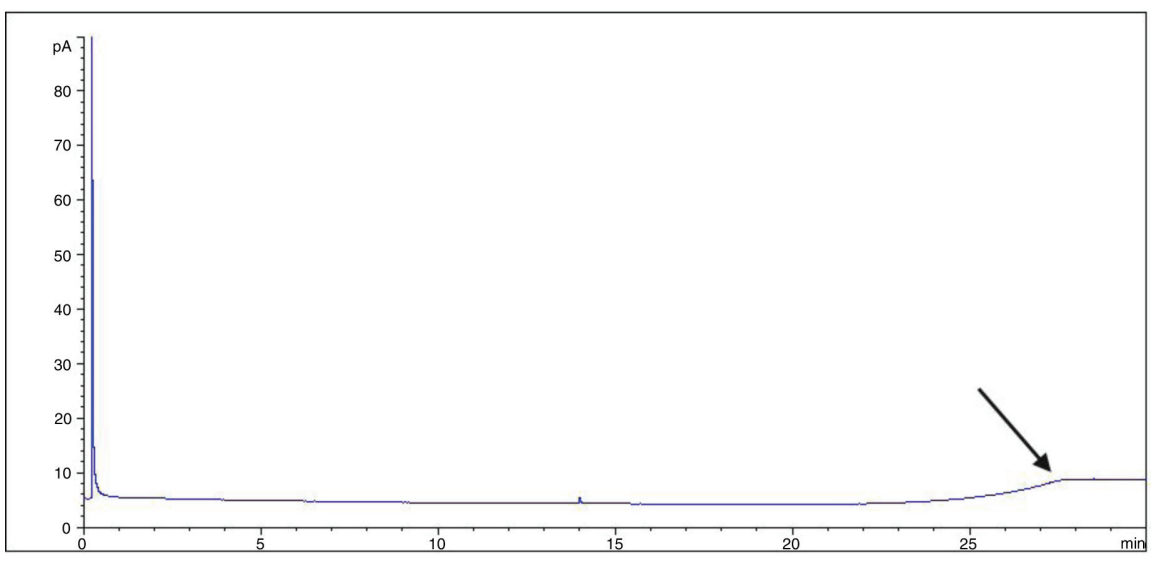

(B)

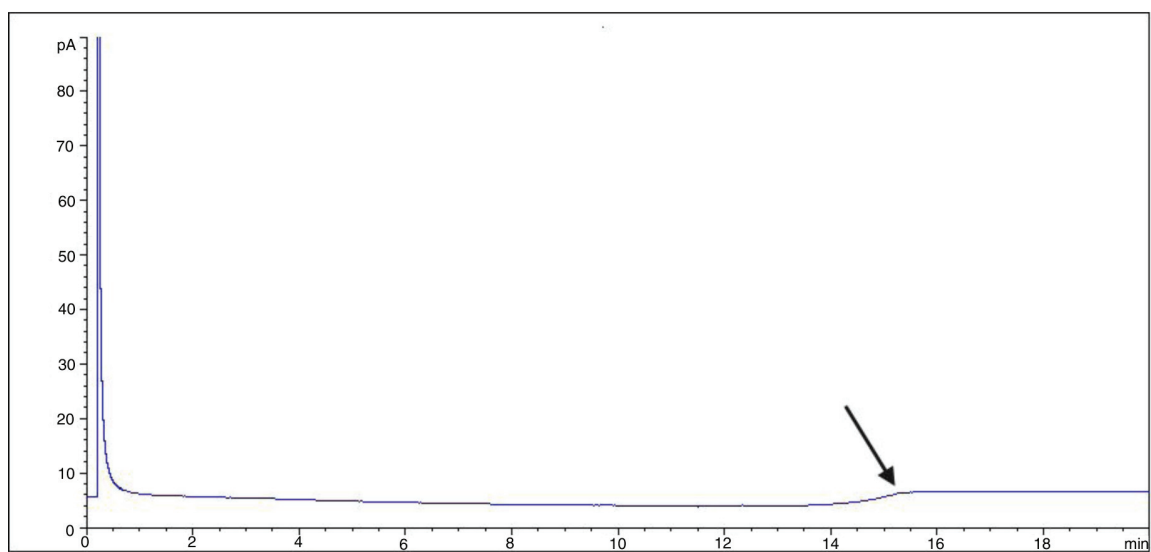

FIGURE 2. GC baseline profiles of n-heptane obtained at different oven temperature rates: A) $12{ }^{\circ} \mathrm{C} \cdot \mathrm{min}^{-1}$; B) $20^{\circ} \mathrm{C} \cdot \mathrm{min}^{-1}$. The arrow indicates the baseline change. 


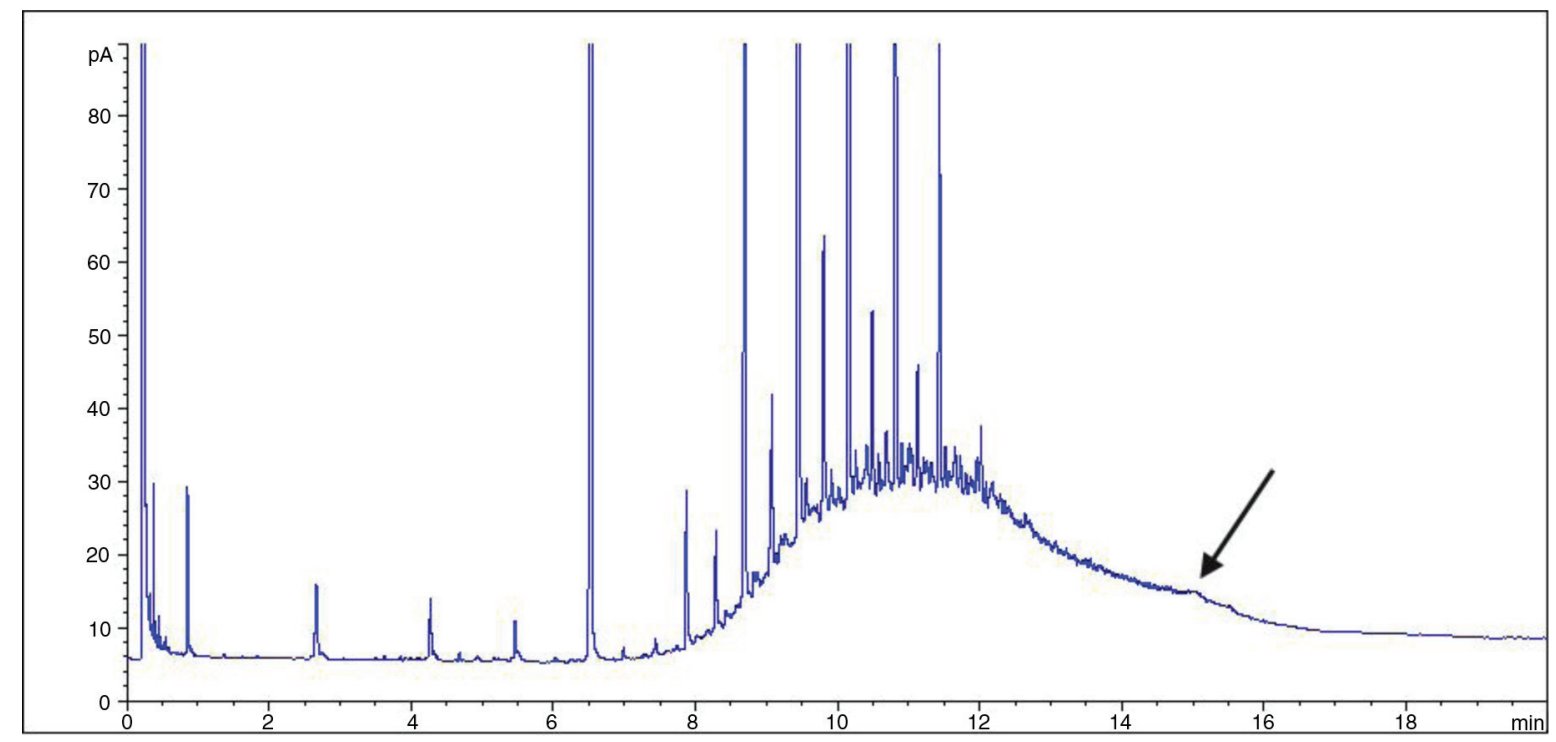

FIGURE 3. GC profile of the first $40 \mathrm{~mL}-\mathrm{n}$-hexane fraction containing $\mathrm{SH}$ from refined olive-pomace oil at oven temperature ramp of $20^{\circ} \mathrm{C} \cdot \mathrm{min}^{-1}$. The arrow indicates the baseline change when using this temperature ramp.

and the mean value $\left(53.9 \mathrm{mg} \cdot \mathrm{kg}^{-1}\right)$ was close to the spiking value $\left(51 \mathrm{mg} \cdot \mathrm{kg}^{-1}\right)$. A draft ISO Standard regarding this method is been evaluated for the determination of aliphatic hydrocarbons in vegetable oils and fats ISO (ISO 2013).

\section{ACKNOWLEDGEMENTS}

The Spanish Ministry of Science and Innovation funded this work (ref. AGL2009-07618). The authors would like to thank Ms. Rosario González Cordones for her assistance in the laboratory.

\section{REFERENCES}

AOCS Official Methods of Analysis. Method Ca 6c-65. Hydrocarbons (Mineral oil); Ca 6c-65; AOCS: Champaign, Illinois, USA, 1997, pp 1-2.

Bastic M, Bastic L, Jovanovic JA, Spiteller G. 1978. Hydrocarbons and other weakly polar unsaponifiables in some vegetable oils. J. Am. Oil Chem. Soc. 55, 886-891. http://dx.doi.org/10.1007/BF02671413.

Biedermann M, Grob K. 2009a. How "white" was the mineral oil in the contaminated Ukrainian sunflower oils? Eur. $J$. Lipid Sci. Technol. 111, 313-319 http://dx.doi.org/10.1002/ ejlt.200900007.

Biedermann M, Fiselier K, Grob K. 2009b. Aromatic hydrocarbons of mineral oil origin in foods: Method for determining the total concentration and first results. J. Agric. Food Chem. 57, 8711-8721. http://dx.doi.org/10.1021/ jf901375e.

Biedermann M, Grob K. 2012. On-line coupled high performance liquid chromatography-gas chromatography for the analysis of contamination by mineral oil. Part 1: Method of analysis. J. Chromatogr. A, 1255, 56-75. http://dx.doi. org/10.1016/j.chroma.2012.05.095.

Cert A, Moreda W. 1998. New method of stationary phase preparation for silver ion column chromatography: Application to the isolation of steroidal hydrocarbons in vegetable oils. J. Chromatogr. A, 823, 291-297. http://dx.doi.org/10.1016/ S0021-9673(98)00183-6.
EC, 2009. Commission Regulation (EC) No 1151/2009 of 27 November 2009 imposing special conditions governing the import of sunflower oil originating in or consigned from Ukraine due to contamination risks by mineral oil and repealing Decision 2008/433/EC; L 313. pp 36-40.

Fiorini D, Fiselier K, Biedermann M, Ballini R, Coni E, Grob K. 2008. Contamination of grape seed oil with mineral oil paraffins. J. Agric. Food Chem. 56, 11245-11250. http:// dx.doi.org/10.1021/jf802244r.

Fiorini D, Paciaroni A, Gigli F, Ballini R. 2010. A versatile splitless injection GC-FID method for the determination of mineral oil paraffins in vegetable oils and dried fruit. Food Control, 21, 1155-1160. http://dx.doi.org/10.1016/j. foodcont.2010.01.011

Fiselier K, Fiorini D, Grob K. 2009a. Activated aluminium oxide selectively retaining long chain $n$-alkanes: Part II. Integration into an on-line high performance liquid chromatography-liquid chromatography-gas chromatography-flame ionization detection method to remove plant paraffins for the determination of mineral paraffins in foods and environmental samples. Anal. Chim. Acta. 634, 102-109. http://dx.doi.org/10.1016/j.aca.2008.12.011.

Fiselier K, Fiorini D, Grob K. 2009b. Activated aluminium oxide selectively retaining long chain $n$-alkanes. Part I, description of the retention properties. Anal. Chim. Acta. 634, 96-101. http://dx.doi.org/10.1016/j.aca.2008. 12.007 .

Fiselier K, Grob K. 2009. Determination of mineral oil paraffins in foods by on-line HPLC-GC-FID: lowered detection limit; contamination of sunflower seeds and oils. Eur. Food Res. Technol. 229, 679-688. http://dx.doi.org/10.1007/ s00217-009-1099-8.

ISO, 2013. International standard methods for animal and vegetable fats and oils. Method 17780. Determination of Aliphatic Hydrocarbons; 17780

IUPAC, 1987. Standard Method 2.611 in Standard Methods for the Analysis of Oils, Fats and Derivatives. Determination of mineral oils in vegetable and animal fats and oils; 2611; Blackwell: Oxford.

Joint Research Centre. 2009. Final report on proficiency test on the determination of mineral oil in sunflower oil.

Lanzón A, Albi T, Cert A, Gracián J. 1994. The hydrocarbon fraction of virgin olive oil and changes resulting from refining. J. Am. Oil Chem. Soc. 71, 285-291. http://dx.doi. org/10.1007/BF02638054. 
Moret S, Barp L, Grob K, Conte LS. 2011. Optimised off-line SPE-GC-FID method for the determination of mineral oil saturated hydrocarbons (MOSH) in vegetable oils. Food Chem. 129, 1898-1903. http://dx.doi.org/10.1016/j. foodchem.2011.05.140

Moret S, Populin T, Conte LS, Grob K, Neukom HP. 2003. Occurrence of $\mathrm{C} 15-\mathrm{C} 45$ mineral paraffins in olives and olive oils. Food Addit. Contam. 20, 417-426. http://dx.doi. org/10.1080/0265203031000098687.

Neukom HP, Grob K, Biedermann M, Noti A. 2002. Food contamination by $\mathrm{C} 20-\mathrm{C} 50$ mineral paraffins from the atmosphere. Atmos. Environ. 36, 4839-4847. http://dx.doi. org/10.1016/S1352-2310(02)00358-8.

Populin T, Biedermann M, Grob K, Moret S, Conte L. 2004. Relative hopane content confirming the mineral origin of hydrocarbons contaminating foods and human milk. Food Addit. Contam. 21, 893-904. http://dx.doi. org/10.1080/02652030400001164.
Tan YA, Kuntom A. 1993. Gas chromatographic determination of hydrocarbons in crude palm kernel oil. J. Assoc. Off. Anal. Chem. 76, 371-376.

Tranchida PQ, Zoccali M, Purcaro G, Moret S, Conte L, Beccaria M, Dugo P, Mondello L. 2011. A rapid multidimensional liquid-gas chromatography method for the analysis of mineral oil saturated hydrocarbons in vegetable oils. J. Chromatogr. A, 1218, 7476-7480. http://dx.doi. org/10.1016/j.chroma.2011.06.089.

Wagner C, Neukom HP, Grob K, Moret S, Populin T, Conte LS. 2001. Mineral paraffins in vegetable oils and refinery byproducts for animal feeds. Mitt. Lebensmittelunters. Hyg. 92, 499-514.

Wagner C, Neukom HP, Galetti V, Grob K. 2001. Determination of mineral paraffins in feeds and foodstuffs by bromination and preseparation on aluminium oxide: method and results of a ring test. Mitt. Lebensmittelunters. Hyg. 92, $231-249$. 